\title{
Editorial - Thirty years of J-DEDS: moving on with new leadership
}

\author{
Christoforos Hadjicostis ${ }^{1} \cdot$ Stéphane Lafortune ${ }^{2}$
}

Published online: 26 January 2021

(C) 2021 The Author(s), under exclusive licence to Springer Science+Business Media, LLC part of Springer Nature

\section{0 years}

Our journal was founded in 1990 by Yu-Chi Ho and the first issue was published in May 1991. Hence, this issue marks the 30th anniversary of J-DEDS! J-DEDS has played a major role in establishing the area of discrete event systems as a key technological domain, at the interface of systems and control theory, computer science, and operations research. Thirty years later, the role of our journal remains as relevant as ever given the new developments in cyberphysical systems and the increasing emphasis on autonomy, security, and learning in these technological systems. In the last few years, our journal has established bridges with the areas of event-based control, formal methods in control, and reactive synthesis in computer science. We have recently published Topical Collections on Smart Manufacturing and on Smart Cities, and we are currently soliciting contributions for a TC on Cybersecurity. We have continued to work closely with several conferences in our field, principally the International Workshop on Discrete Event Systems (WODES). We solicit and publish survey and tutorial papers on a variety of topics, as such papers are very important to the research community. We look forward to continuing to serve the broad discrete event systems community in the years to come. We welcome your contributions!

\section{Farewell}

After six years of serving J-DEDS as its third Editor-in-Chief, following Yu-Chi Ho and Xiren Cao, I have decided it is time to step down from that role. I have enjoyed working with all the members of the Editorial Board: Department Editors, Associate Editors, and Advisory Board. I sincerely thank them all for their efforts. I also thank all the reviewers who have helped to maintain the high standards of J-DEDS over the years. I am delighted that a leader in our field, who has been serving on the Editorial Board of J-DEDS for many years, Christoforos

Christoforos Hadjicostis chadjic@ucy.ac.cy

1 University of Cyprus, Nicosia, Cyprus

2 The University of Michigan, Ann Arbor, MI, USA 
Hadjicostis of the University of Cyprus, has kindly agreed to be the new Editor-in-Chief, starting with this first issue of 2021. I wish Chris the best and I know that J-DEDS will thrive under his leadership.

Stéphane Lafortune

\section{Moving forward}

I am delighted to assume the Editor-in-Chief position for J-DEDS. Under Stéphane Lafortune's leadership in the last six years, J-DEDS has solidified its position as one of the flagship journals of the DES community, maintaining a steady stream of high-quality papers, a set of reviewers with diverse skill sets, and advisory and editorial boards of international caliber across the research areas covered by the journal. I am sure I speak on behalf of the entire DES community when I thank Stéphane for his excellent handling of J-DEDS matters in the last six years. I am honored to follow the steps of such a devoted and visionary Editor-inChief, and extremely fortunate to assume the handling of a journal in such outstanding state.

I am also pleased to report some changes to our Editorial and Advisory Boards.

Department Editors: Jan Komenda and Carla Seatzu who were previously serving as Associate Editors have agreed to serve as Department Editors. I would like to take this opportunity to welcome Jan and Carla to their new role, and also thank Alessandro Giua, who has decided to step down from a Department Editor position after many years of service to the journal.

Associate Editors: I am pleased to announce that João Carlos Basilio, Thao Dang, Dimitri Lefebvre, Thomas Masopust, Anne-Kathrin Schmuck, and Xiang Yin have accepted positions as Associate Editors for J-DEDS. Meanwhile, Sophie Pinchinat and Bart De Schutter have decided to step down after handling numerous papers as Associate Editors for the journal. I would like to thank, on behalf of J-DEDS, Sophie and Bart for their efforts as AE's, and also give a warm welcome to João, Thao, Dimitri, Thomas, Anne, and Xiang.

Advisory Board: Stéphane Lafortune will be joining the advisory board of J-DEDS, along with Panos J. Antsaklis of the University of Notre Dame and Edwin Chong of Colorado State University. Murray Wonham has decided to step down from the journal's advisory board after a long-term presence. We are grateful to Murray for his many contributions to our journal and the DES community as a whole.

I am looking forward to working with all members of our advisory board and our outstanding group of Department and Associate Editors for the continuous success of our journal. I am also reaching out to all members of the DES community for any suggestions or proposals they may have about how the journal can move forward with continued success.

Christoforos Hadjicostis 


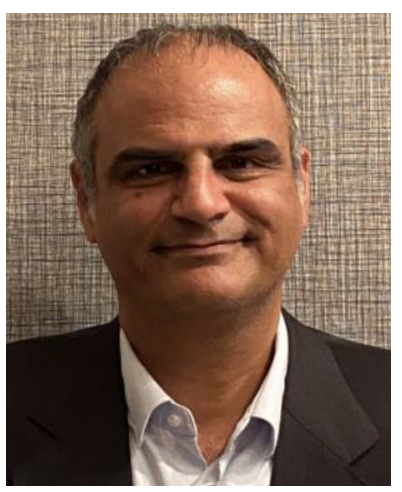

Christoforos N. Hadjicostis is Professor of Electrical and Computer Engineering and Interim Director of the FOSS Research Center for Sustainable Energy at the University of Cyprus. He received S.B. degrees in electrical engineering, computer science and engineering, and mathematics, in 1993, the M.Eng. degree in electrical engineering and computer science, in 1995, and the $\mathrm{Ph} . \mathrm{D}$. degree in electrical engineering and computer science, in 1999, all from Massachusetts Institute of Technology, Cambridge, MA. Before joining the University of Cyprus, he was with the Department of Electrical and Computer Engineering, the Coordinated Science Laboratory, and the Information Trust Institute, at the University of Illinois at Urbana-Champaign, Champaign, IL. His research focuses on fault diagnosis and tolerance in distributed dynamic systems, error control coding, monitoring, diagnosis and control of large-scale discrete-event systems, and applications to network security, anomaly detection, energy distribution systems, and medical diagnosis. Dr. Hadjicostis currently serves as the Editor-in-Chief of the journal Discrete Event Dynamic Systems: Theory and Applications. He is a Fellow of IEEE (2020).

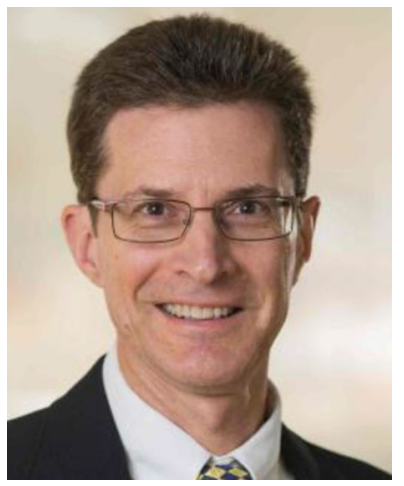

Stéphane Lafortune is the N. Harris McClamroch Collegiate Professor of Electrical Engineering and Computer Science at the University of Michigan, Ann Arbor, USA. He obtained his degrees from École Polytechnique de Montréal (B.Eng., 1980), McGill University (M.Eng., 1982), and the University of California at Berkeley (PhD, 1986), all in electrical engineering. He is a Fellow of IEEE (1999) and of IFAC (2017). His research interests are in discrete event systems and include multiple problem domains: modeling, diagnosis, control, optimization, and applications to computer and software systems. He co-authored, with C. Cassandras, the textbook Introduction to Discrete Event Systems (2nd Edition, Springer, 2008). He served as Editor-in-Chief of the journal Discrete Event Dynamic Systems: Theory and Applications from 1/2015 to 12/2020. 